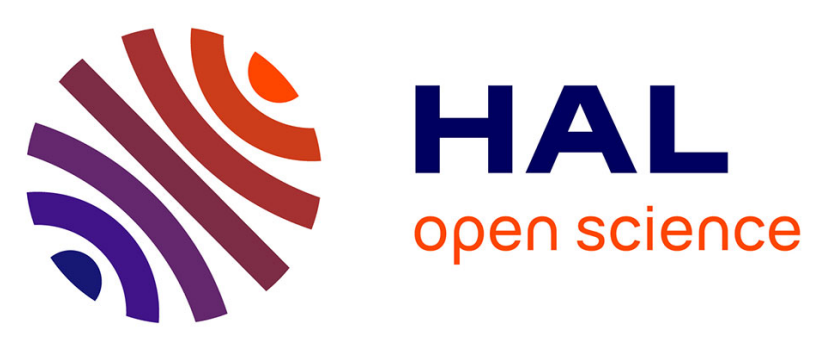

\title{
Dependence of the irradiation-induced growth kinetics of satellites on the nanoclusters dimension
}

\author{
G. Rizza, Y. Ramjauny, T. Gacoin, S. Henry
}

\section{To cite this version:}

G. Rizza, Y. Ramjauny, T. Gacoin, S. Henry. Dependence of the irradiation-induced growth kinetics of satellites on the nanoclusters dimension. Maria Grazia Grimaldi, Giuliana Impellizzeri, Salvatore Mirabella and Lucia Romana. 15th International Conference on Ion Beam Modification of Materials - IBMM 2006, Sep 2006, Taormina, Italy. Elsevier, 257, pp.15-19, 2007, 10.1016/j.nimb.2006.12.113 . in2p3-00123836

\section{HAL Id: in2p3-00123836 https://hal.in2p3.fr/in2p3-00123836}

Submitted on 11 Jan 2007

HAL is a multi-disciplinary open access archive for the deposit and dissemination of scientific research documents, whether they are published or not. The documents may come from teaching and research institutions in France or abroad, or from public or private research centers.
L'archive ouverte pluridisciplinaire HAL, est destinée au dépôt et à la diffusion de documents scientifiques de niveau recherche, publiés ou non, émanant des établissements d'enseignement et de recherche français ou étrangers, des laboratoires publics ou privés. 


\title{
Dependence of the irradiation-induced growth kinetics of satellites on the nanoclusters dimension
}

\author{
G. Rizza* \\ Laboratoire des Solides Irradiés, \\ CEA/DRECAM-Ecole Polytechnique-CNRS UMR 7642 \\ Ecole Polytechnique 91128 Palaiseau Cedex, France \\ Phone: +33.1.69.33.45.10 \\ Fax number: +33 1.69.33.30.22 \\ e-mail : giancarlo.rizza@polytechnique.edu \\ Y. Ramjauny ${ }^{\dagger}$ T. Gacoin,${ }^{\ddagger}$ and S. Henry ${ }^{\S}$
}

(Dated: December 20, 2006)

\begin{abstract}
Irradiation with $\mathrm{MeV}$ gold ions of embedded $\mathrm{Au}$ nanoclusters in silica matrix results in the formation of a ring of satellites in its surrounding. We show that changing the initial nanoclusters size modifies both the size and the density of the satellites, and therefore alters their kinetic growth. Finally we discuss the limitation of the ion implantation technique to form a model system to study the satellites kinetic growth and we propose a new approach based on the chemical synthesis of metallic nanoparticles to obtain the proper configuration.

PACS numbers: 61.80.Jh, 61.46.-w, 68.37.Lp, 81.07.BC

\footnotetext{
*Electronic address: giancarlo.rizza@polytechnique.edu

${ }^{\dagger}$ Laboratoire des Solides Irradiés, CEA/DRECAM-Ecole Polytechnique-CNRS UMR 7642, Ecole Polytechnique 91128 Palaiseau Cedex, France

${ }^{\ddagger}$ Groupe de Chimie du Solide, Laboratoire de Physique de la Matière Condensée, UMR CNRS 7643, Ecole Polytechnique, 91128 Palaiseau, France

${ }^{\S}$ CSNSM, CNRS/IN2P3; Univ Paris-Sud, UMR8609, ORSAY-Campus, F-91405, France
} 


\section{INTRODUCTION}

The study of sub-micrometer particles is receiving an increasing attention due to their specific properties with potential applications in the growing domain of nanotechnologies [1-3]. Ion beam synthesis (IBS) refers to the possibility to synthesize nanoclusters (NCs) by having recurse to the irradiation, and represents a promising technique to form nanostructures with unique properties by tailoring their size and their spatial distribution. In particular, ion implantation, normally coupled with post-implantation thermal annealing, is a versatile technique for the fabrication of embedded NCs [3]. The nanostructure synthesis by the ion implantation technique is relatively well understood and usually separated in different stages [4]: i) supersaturation of the matrix by implanted solute atoms, ii) NCs nucleation and iii) growth by solute depletion of supersatured solid solution. iv) a coarsening process (Ostwald ripening if the mass is conserved) when the solute concentration is reduced below a critical level. High implantation dose may result in NCs coalescence.

On the other hand, few works exist on the ion beam modification processes, where the energy released by the energetic ions is used to modify already formed NCs. Experimentally, it has been shown that the irradiation favors the satellites formation around the original NC [5-9]. In particular, ion irradiation can be used to induce the selective precipitation of one element in bimetallic alloys [6]. Moreover, the narrowing of the NCs size distribution and its displacing towards the small NC dimension have been evidenced [10-12]. Finally, it has been shown that ion irradiation can be the used to modify the morphology of the embedded NCs $[13,14]$. Besides this, only few models and simulations account for the experimental results $[15,16]$.

Therefore a deeper physical understanding on the behavior of the embedded NCs under ion irradiation is a prerequisite for appropriate control of the fabrication process.

Here we are interested in the behavior of the satellites formed around the NCs under ion irradiation. In particular, with respect to the ion implantation, where the solute concentration is defined by the implantation dose, the irradiation, via the ion mixing, allows the solute to be continuously added to the system, where the original NC becomes a solute reservoir. As the complete description of the growth kinetic process needs the knowledge of both the size and density of the satellites as a function of the irradiation fluence, insight into the kinetic mechanisms requires, besides the control of the irradiation parameter, also 
the careful control of the properties of the embedded nanoparticles. In this regard, the aim of the present work is to describe how the growth kinetics of the satellites can be influenced by the initial dimension of the embedded NCs.

\section{EXPERIMENTAL}

For this study $\mathrm{Au}$ NCs in amorphous $\mathrm{SiO}_{2}$ was chosen as a model system because of the low solubility of $\mathrm{Au}$ in $\mathrm{SiO}_{2}$ and its relative large mass difference with respect to $\mathrm{Si}$ and O which facilitates the particle observation in Transmission Electron Microscopy (TEM) analysis.

In order to have a controlled initial spatial and size distribution, the NCs were chemically synthesized and then sandwiched between two silica layers. The synthesis of the Au NCs is achieved following the method of Turkevitch $[12,17]$. The embedding of the gold particles is achieved in four steps. The first step is the deposition of a sol-gel silica film on a Si wafer. The film is densified by calcination at $450^{\circ} \mathrm{C}$ for $4 \mathrm{~h}$. The obtained film has a thickness of $255 \mathrm{~nm}$ as determined by ellipsometry. The second step is the grafting of the gold particle at the surface of the silica film. This was done following a process derived from previous published results [18]. First the surface of silica is functionalized with an aminosilane as a surface coupling agent. Grafting of the gold particles is achieved by simple immersion of the functionalized substrates into colloidal gold solution. The surface amount of grafted particles depends on the immersion time. The control of the size and the spatial distribution of $\mathrm{Au}$ NCs was checked with the Scanning Electron Microscopy (SEM) technique. Finally the particles are embedded in the sol-gel silica layer by achieving the deposition of a second silica layer under the same conditions as the first one. A control experiment performed on a glass substrate instead of silicon, allowed to check that the spin coating deposition of the second silica layer did not remove the particles. To finish, the samples were annealed under $\mathrm{H}_{2}$ - $\mathrm{Ar}$ atmosphere at $900^{\circ} \mathrm{C}$ during 1 hour. It worth noting that with this method we were able to synthesize Au NCs embedded in a silica matrix with a symmetric size distribution and a dispersion of $2.1 \mathrm{~nm}$ [12]. Larger size dispersion is simply obtained by modifying the NCs synthesis time in the Turkevitch procedure $[12,17]$

All the irradiations described in the present work were performed with the ARAMIS accelerator, [19], at the CSNSM laboratory (Orsay, France). NCs with an initial size ranging 
from 8 up to $30 \mathrm{~nm}$ were irradiated with $4 \mathrm{MeV} \mathrm{Au}{ }^{2+}$ ions at a fluence of $1.5 \times 10^{16} \mathrm{~cm}^{-2}$ at room temperature $(\mathrm{T}=300 \mathrm{~K})$, figure 1 . The nuclear energy loss $\left(\mathrm{S}_{n}=7.5 \mathrm{keV} . \mathrm{nm}-1\right)$ as well as the implantation depth of the $\mathrm{Au}$ ions $\left(\mathrm{R}_{p} \sim 1 \pm 0.1 \mu \mathrm{m}\right)$ were estimated using SRIM2000 CODE $[20,21] . \mathrm{R}_{p}$ is at least five times the depth at which NCs were synthesized (200 nm). Thus implanted Au does not interact with the Au NCs. The samples characterization was performed by transmission electron microscopy (TEM) with $300 \mathrm{keV}$ Philips CM30. The average size, size distribution and spatial distribution of Au NCs were obtained in planar transmission electron microscopy (P-TEM). Transmission Electron Microscopy micrographs were processed with a slow scan CCD camera and analyzed with the Digital Micrograph program.

\section{RESULTS AND DISCUSSION}

Figures 2(a-d) show the formation of a satellite ring around the Au NCs of different sizes irradiated with $4 \mathrm{MeV}$ Au ions at a fluence of $1.5 \times 10^{16} \mathrm{~cm}^{-2}$. As all the NCs are embedded in the same dielectric matrix, the irradiation conditions are the same for all the NCs and the only varying parameter is the $\mathrm{NC}$ diameter, or its volume. Observing figure 2 we note that i) the satellites size, ii) their distance from the original $\mathrm{NC}$ and iii) their number seems to scale with the NCs size. TEM micrographs show that the satellites close to the NC surface are systematically larger than that formed at larger distances. Their nucleation and growth is directly sustained by the NC dissolution, where the latter is considered a solute reservoir. We call these satellites of first generation. A second generation of satellites nucleates when the first generation of satellites is large enough to create, via the irradiation mixing, a solute supersaturation at increasing distances from the $\mathrm{NC}$ surface, $\mathrm{d}_{N C}$. As for increasing value of $\mathrm{d}_{N C}$ the strength of the solute reservoir is reduced, because the solute is spread over a larger volume, $\sim \mathrm{d}_{N C}^{3}$, the solute concentration decreases with the distance from the NC and the nucleation and growth of new satellites remains limited. As the study of such a system is complicated, we limited our investigation to the evolution of the first generation of satellites, those close to the original NC. Experimentally they are found in an annular region around the $\mathrm{NC}$ with a thickness ranging between $1-1.5 \mathrm{R}_{N C}$, where $\mathrm{R}_{N C}$ is the $\mathrm{NC}$ radius.

The corresponding satellites size distributions (SSD) are shown in figures 3(a-e). For the smallest nanoparticle size, $5.8 \mathrm{~nm}$, the $\mathrm{SSD}$ is asymmetric with a tail towards the smaller 
size, figure 3a. Increasing the NC size to $8.7 \mathrm{~nm}$ results in quite symmetric SSD, figure 3b. Further increase of the NC size, up to $16.7 \mathrm{~nm}$, shows that the SSD is again asymmetric but this time with a tail towards the large satellite diameter, figure 3c. Finally, for the largest NC considered in the present work, $25.1 \mathrm{~nm}$, the SSD becomes bimodal, figure 3d. The bimodal shape of the SSD can be understood thinking that when the growing satellites reach a "critical" size their contribution to the solute concentration becomes large enough to enhance the nucleation of new satellites in their vicinity. On the other extreme, the dimension of the smallest NCs is not sufficient to sustain the satellites growth, and the SSD remains unimodal. This is the case for the NCs of $5.8 \mathrm{~nm}$ and $8.7 \mathrm{~nm}$. An intermediary situation is found for the $16.7 \mathrm{~nm} \mathrm{NC}$ with. Here, the contribution of the larger satellites to the supersaturation is sufficient to allow the nucleation of new satellites in their surrounding leading to a distribution with a tail towards the larger NC sizes.

Figure 4 reports the variation of the average satellite diameter as a function of the NC dimension. It is found that the satellites mean diameter increases from $1.9 \mathrm{~nm}$ up to 3-3.5 $\mathrm{nm}$ for NC size ranging from $5 \mathrm{~nm}$ up to $10-12 \mathrm{~nm}$. Further increasing of the NC size results in the saturation of the average satellites diameter to the value of about $4 \mathrm{~nm}$.

The relation between the number of the satellites and the NC size is shown in figure 5a. Linear relation seems to exist up to about $20 \mathrm{~nm}$, then a saturation appears. The satellites density can be calculated using the number of satellites of figure $5 \mathrm{a}$ and the annular surface containing the satellites defines as:

$$
S=\pi\left(R_{N C}+d_{N C}\right)^{2}-\pi R_{N C}^{2}
$$

where $\mathrm{d}_{N C}$ is the distance from the $\mathrm{NC}$ surface and $\mathrm{R}_{N C}$ the $\mathrm{NC}$ radius. The result is reported in figure 5b. The density scales approximatively with the inverse of the NC radius, $\rho_{\text {satellites }} \sim 1 / \mathrm{R}_{N C}$. This is due to the fact that the annular surface increases faster $\left(\sim \mathrm{R}_{N C}^{2}\right)$ than the number of satellites $\left(\sim \mathrm{R}_{N C}\right)$.

\section{CONCLUSION}

In conclusion, we showed that irradiation of NCs with different sizes leads to different values of both satellites size and density. In particular, the satellite size linearly scales with the NCs size before to saturate, whereas the density ranges approximatively as the inverse of 
the NCs radius. For example changing the NC size from $5 \mathrm{~nm}$ to $30 \mathrm{~nm}$ we obtain a satellite size of $1.9 \mathrm{~nm}$ and $4 \mathrm{~nm}$ and a density of $0.083{\text { at. } m^{-2} \text { and } 0.014 \text { at.nm }}^{-2}$, respectively, which represents a variation of about $47 \%$ in the size and a $17 \%$ in the density estimation. It is worth noting that also the shape of the size distribution function depends on the NCs size. SSD presents a tail towards the small NCs size if the NCs are small $(5.8 \mathrm{~nm})$, a symmetric shape for NCs of about $10 \mathrm{~nm}$, a tails towards the large NCs size for NCs of about $16 \mathrm{~nm}$

and bimodal shape for larger NCs $(25 \mathrm{~nm})$. It is clear that starting with a large NCs size distribution introduces errors in the measure of the kinetic processes under irradiation.

In order to study the kinetics growth is therefore important to start with the narrowest possible size distribution profile. In this regards both ion implantation and ion mixing, inducing balling-up of a continuous thin film are not adapted techniques, because the control of the size and the spatial dispersion of the embedded NCs is one of their main limitation.

On the other hand, the chemical synthesis of metallic NCs and the following sandwiching between two amorphous layers allows to overcome this constraint, and to irradiate a model system where the size, the spatial distribution as wall as the NCs concentration are perfectly controlled during the sample preparation [12].

\section{Acknowledgments}

We gratefully acknowledge C. Boukari and L. Delbecq for their contribution to this work. 


\section{References}

[1] In: F. Gonella and P. Mazzoldi, Editors, Handbook of Nanostructured Materials and Nanotechnology Vol. 4, Academic Press, San Diego (2000).

[2] P. Mazzoldi, G. Mattei, C. Maurizio, E. Cataruzza and F. Gonella, Metal Alloy Nanoclusters by Ion Implantation in Silica, in Engineering Thin Films and Nanostructures with Ion Beams, Chap. 7, edited by Emile Knystautas (CRC Press), 2005, pp. 81-158

[3] A. Meldrum, L.A. Boatner and C.W. White, Nucl. Instr. and Meth. B 178 (2001) 7

[4] M. Strobel, K.H. Heining, W. Möller, A. Meldrum, D.S. Zhou, C.W. White, R.A. Zuhr, Nucl. Instr. Meth. B 147 (1999) 343

[5] G.C. Rizza, M. Strobel, K.H. Heinig, H. Bernas, Nucl. Instr. Meth. B 178 (2001) 78

[6] G. Mattei, G. De Marchi, C. Maurizio, P. Mazzoldi, C. Sada, V. Bello, G. Battaglin, Phys. Rev. Lett. 90 (2003) 855502

[7] G. Mattei, G. Battaglin, V. Bello, G. De Marchi, C. Maurizio, P. Mazzoldi, M. Parolin, C. Sada, J. Non-Cryst. Solids 322 (2003) 17

[8] V. Bello, G. De Marchi, C. Maurizio, G. Mattei, P. Mazzoldi, M. Parolin, C.Sada, J. NonCryst. Solids 345-346 (2004) 685

[9] G. Mattei, V. Bello, P. Mazzoldi, G. Pellegrini, C. Sada, C. Maurizio, G. Battaglin, Nucl. Instr. Meth. B 240 (2005) 128

[10] B. Schmidt. K.H. Heinig, A. Muecklich, Mater. Res. Soc. Symp. Proc. 647 (2001) 011.20.1

[11] P. Kluth, M. Ridgway, Nucl. Instr. Meth. B 242 (2006) 458

[12] G. Rizza, H. Cheverry, T. Gacoin, S. Henry, J. Appl. Phys. accepted

[13] C. D’Orleans, J.P. Stoquert, C. Estournes, C. Cerruti, J.J. Grob, J.L. Guille, F. Haas, D. Muller, M. Richard-Plouet, Phys. Rev. B 67 (2003) 220101

[14] JJ. Penninkhof, T. van Dillen, S. Roorda, C. Graf, A. van Blaaderen, A.M. Vredenberg, A. Polman Nucl. Instr. Meth. B 242 (2006) 523

[15] K.H. Heinig, T. Müller, M. Strobel, B. Schmidt, W.Möller, Appl. Phys. A 77 (2003) 17

[16] M. Strobel, K.H. Heinig, W.Möller, Mater. Res. Soc. Symp. Proc. 647 (2001) 23

[17] J. Turkevich, P. Cooper Stevenson, J. Hillier, Disc. Farad. Soc. 11 (1951) 55

[18] O. Seitz, M.M. Chehimi, E. Cabet-Deliry, S. Truong, N. Felidj, C. Perruchot, S.J. Greaves, 
J.F. Watts, Colloids and Surfaces A: Physiochem. Eng. Aspects 218 (2003) 225/239

[19] E. Cotterau, J. Camplan, J. Chaumont, R. Munier, H. Bernas, Nucl. Instr. Meth. B 45 (1990) 293

[20] J.F. Ziegler, J.P. Biersack, U. Littmark, The stopping ranges and ranges of ions in solids (Pergamon Press, New York, 1985)

[21] http://www.srim.org 


\section{Figure captions}

Figure 1: TEM micrograph of the unirradiated sample

Figure 2: TEM micrograph of NCs with different sizes irradiated at a fluence of $1.5 \times 10^{16}$ $\mathrm{cm}^{-2}$ with $4 \mathrm{MeV} \mathrm{Au}$ ions at room temperature. a) $5.8 \mathrm{~nm}$, b) $8.7 \mathrm{~nm}$, c) $16.7 \mathrm{~nm}$ and d) $25.1 \mathrm{~nm}$.

Figure 3: Satellites size distribution as a function of the NC size, as in figure 1.

Figure 4: Relation between the NC size and the mean satellite size for a sample irradiated at a fluence of $1.5 \times 10^{16} \mathrm{~cm}^{-2}$ with $4 \mathrm{MeV} \mathrm{Au}$ ions at room temperature.

Figure 5: a) Number of satellites and b) the corresponding density as a function of the NCs size. 


\section{Figures}

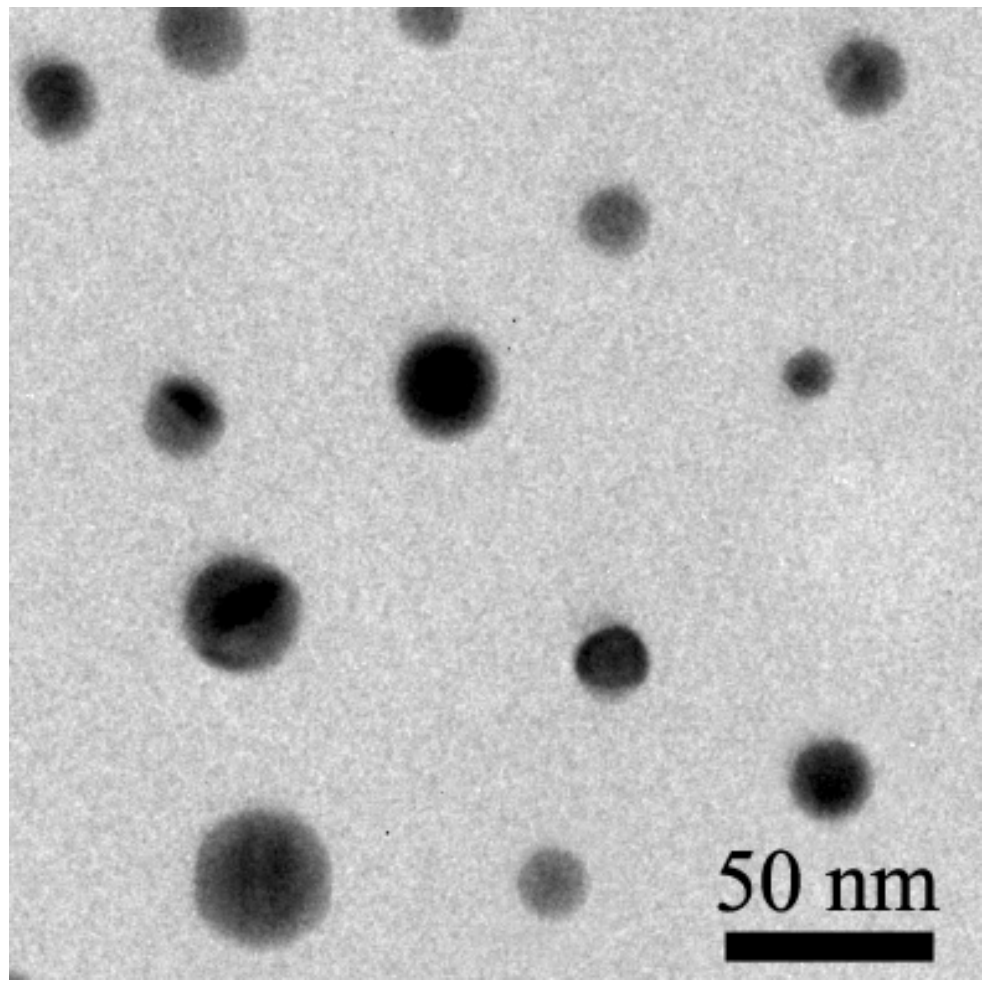

FIG. 1: TEM micrograph of the unirradiated sample 

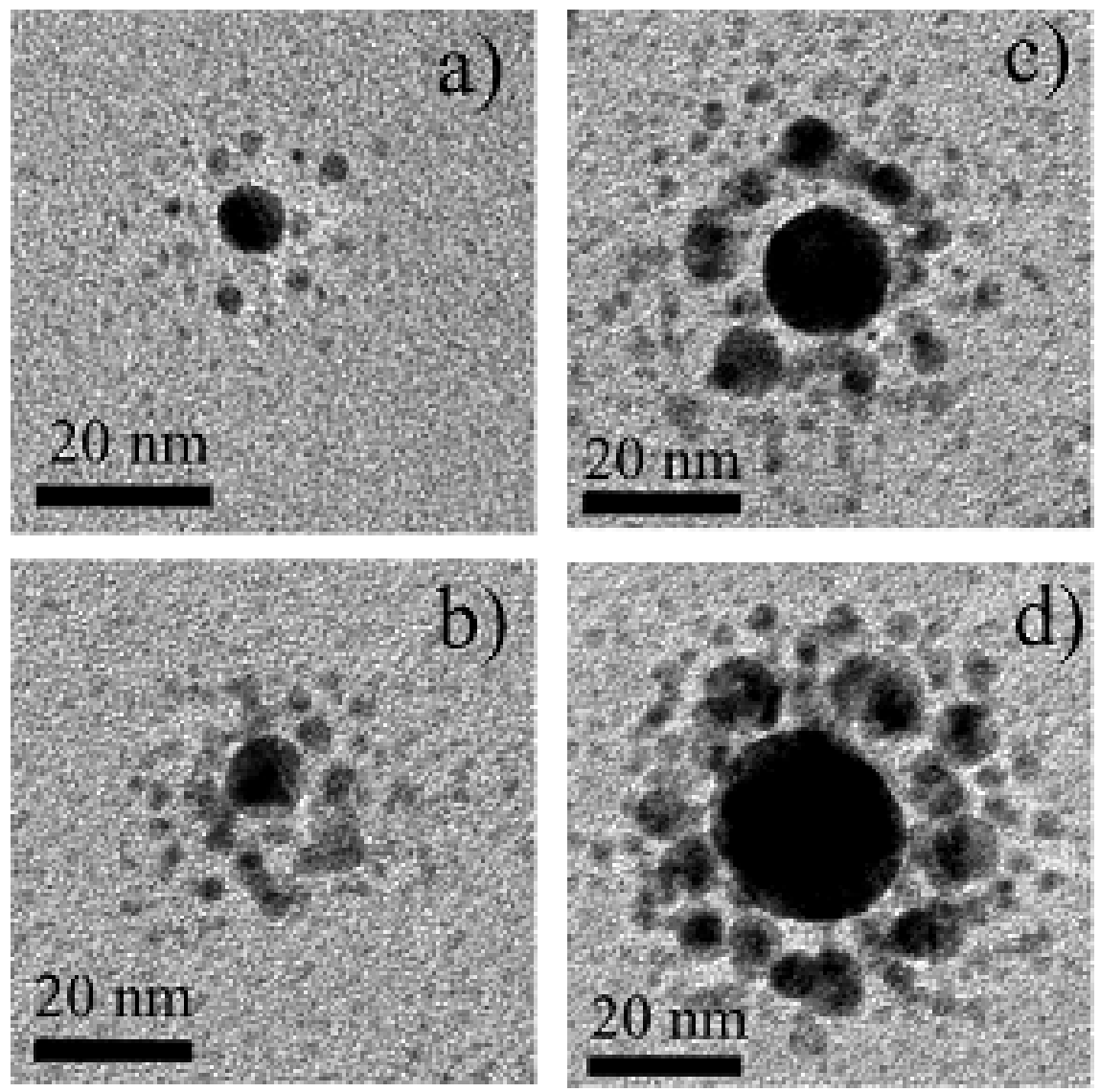

FIG. 2: TEM micrograph of NCs with different sizes irradiated at a fluence of $1.5 \times 10^{16} \mathrm{~cm}^{-2}$ with $4 \mathrm{MeV} \mathrm{Au}$ ions at room temperature. a) $5.8 \mathrm{~nm}$, b) $8.7 \mathrm{~nm}$, c) $16.7 \mathrm{~nm}$ and d) $25.1 \mathrm{~nm}$. 

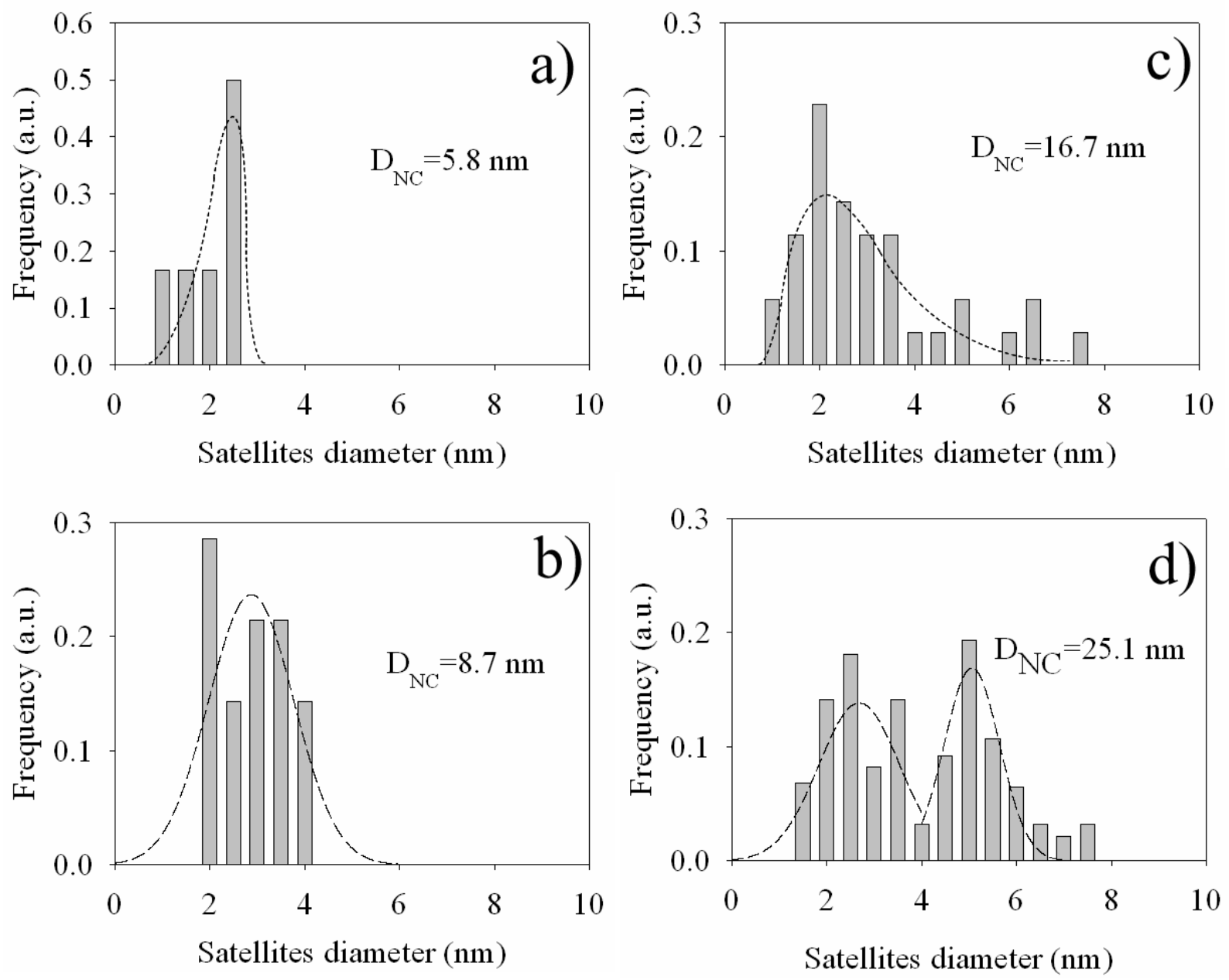

FIG. 3: Satellites size distribution as a function of the NC size, as in figure 1 


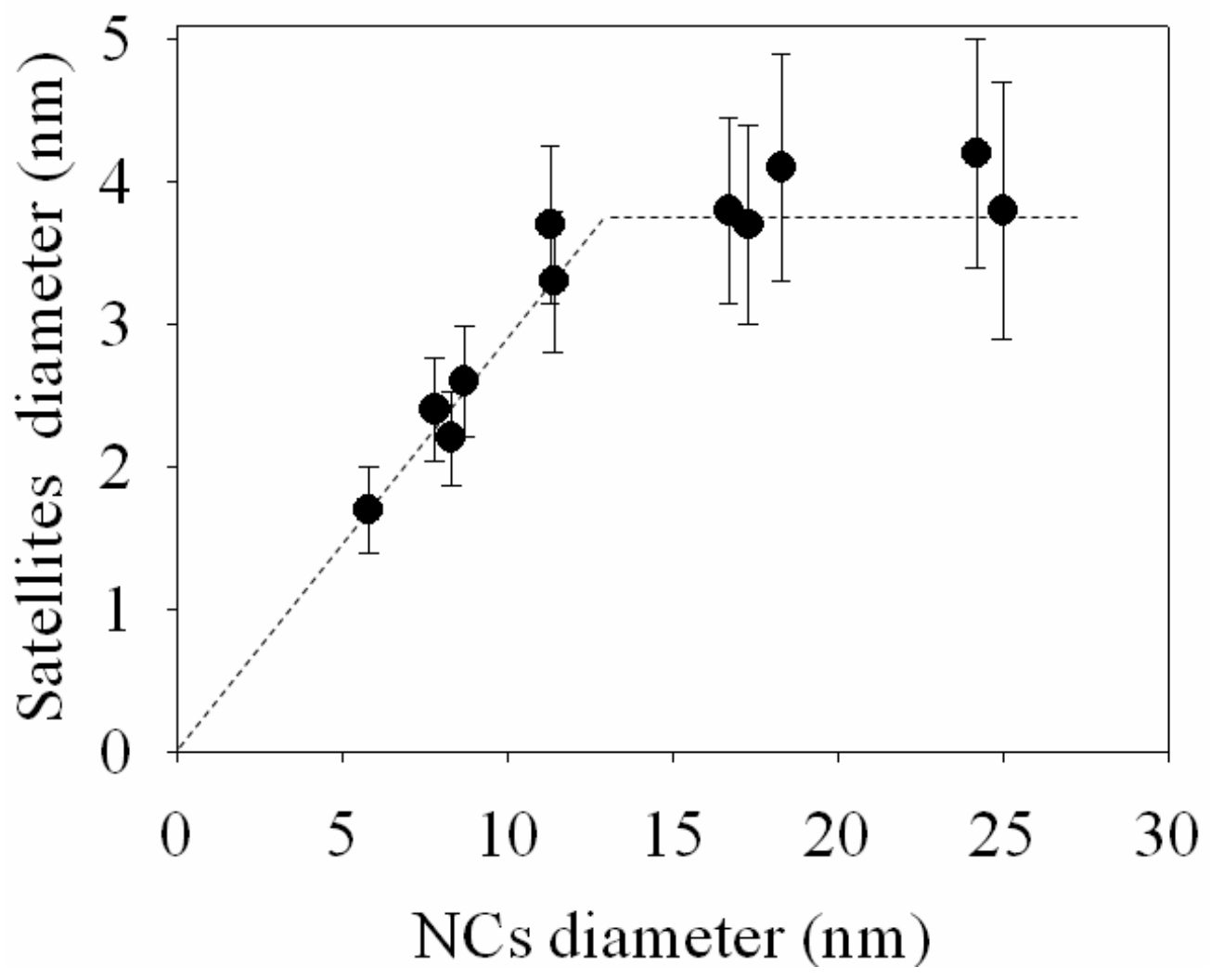

FIG. 4: Relation between the NC size and the mean satellite size for a sample irradiated at a fluence of $1.5 \times 10^{16} \mathrm{~cm}^{-2}$ with $4 \mathrm{MeV} \mathrm{Au}$ ions at room temperature. 

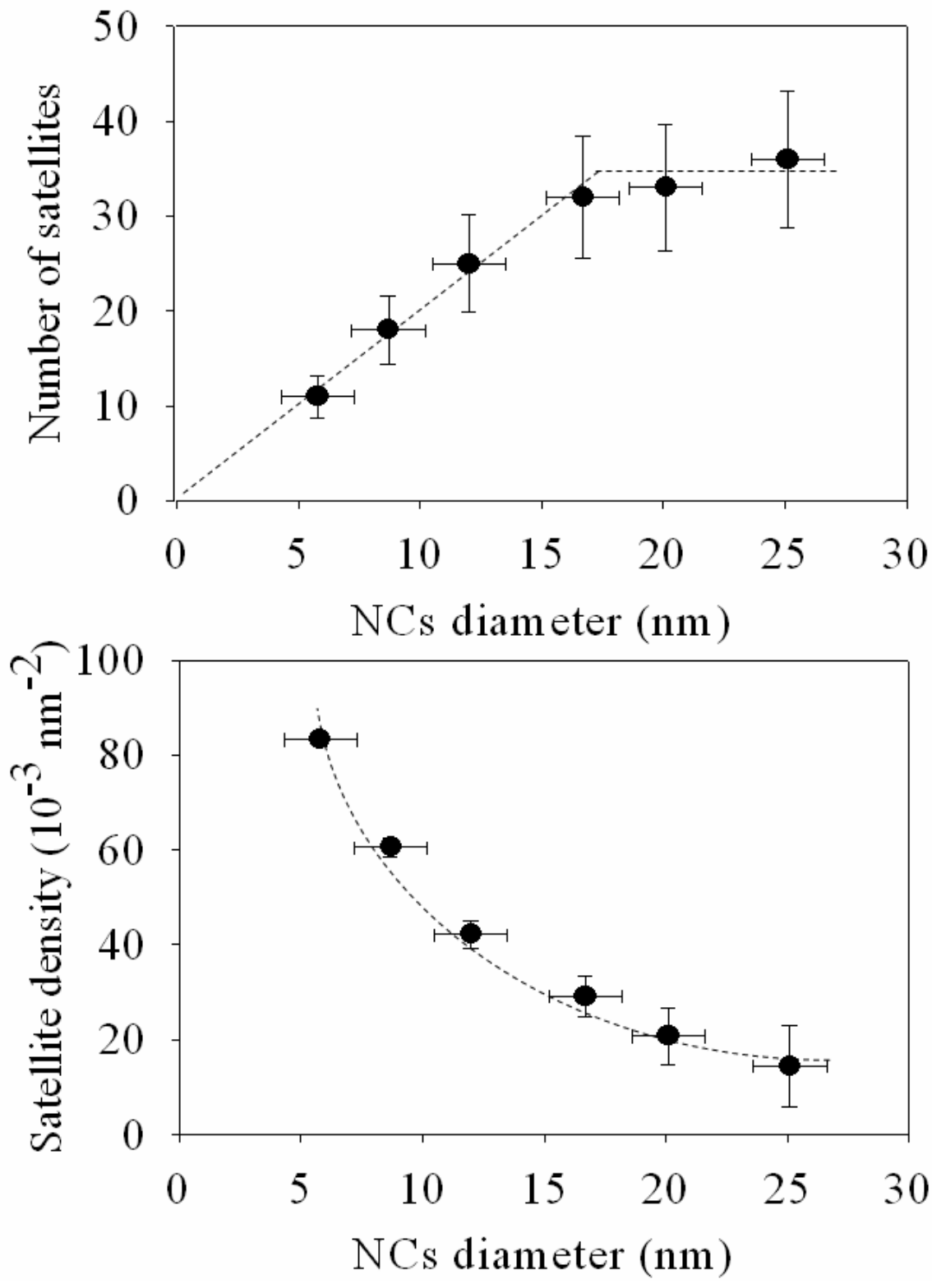

FIG. 5: a) Number of satellites and b) the corresponding density as a function of the NCs size. 